\title{
'What you cannot imagine': spirituality in Akram Khan's Vertical Road
}

\author{
Jayne Stevens De Montfort University
}

KEYWORDS: Akram Khan, intercultural performance, contemporary dance, progressive spirituality, creativity.

\begin{abstract}
This article considers the interface between artistic and spiritual inquiry through an examination of Vertical Road (2010), an ensemble performance work by the British contemporary choreographer Akram Khan. Khan is well known for his cross-cultural explorations, critical appreciation of which has tended to focus on the hybrid nature of his movement vocabulary and aesthetic. This article considers the intercultural nature of his work in terms of the ideas, beliefs and values that it embodies. In particular it examines Vertical Road in relation to some key tenets of contemporary progressive spirituality. It suggests that Vertical Road provides a poetic and insightful reflection on our contemporary spiritual condition.
\end{abstract}

'I died from minerality and became vegetable;

And from vegetativeness I died and became animal

I died from animality and became man.

Then why fear disappearance through death?

Next time I shall die

Bringing forth wings and feathers like angels;

After that, soaring higher than angels -

What you cannot imagine,

I shall be that.'

This poem by the thirteenth century Islamic poet and mystic, Jalāl al-Dīn Rūmī forms the main programme note accompanying performances of Vertical Road, the most recent, full length ensemble work by the contemporary British choreographer, Akram Khan. Vertical Road premiered at Curve in Leicester in September 2010 and has since toured internationally. A twenty six month tour will see the work performed throughout Europe (including Russia), the Middle East and Asia, both North and South America and in Australia. It is a work that is proving to have global-inter-national and inter-culturalappeal. It is also a work, as Rūm̄̄'s poem signals, in which concerns about spirituality are central. This article investigates the nature of the spiritual enquiry embedded in and embodied by Vertical Road. It does so by examining Vertical Road within the context of Khan's work generally and considering it in relation to aspects of contemporary spirituality. Critical appreciation of Khan's work has tended to focus on its cross-cultural significance 
primarily in relation to identity politics and hybrid performance practices. This special issue of the Journal of Dance and Somatic Practices provides an apt and timely opportunity to consider his work as a reflection on and embodiment of inter-cultural ideas, values and practices concerning spirituality.

In a previous issue of this journal, Amanda Williamson (2010) mapped a territory for scholarly study of contemporary spirituality and dance. In doing so she noted the relative under-representation of such study in current dance studies literature. Whereas recently some academic and professional disciplines, notably health care, social and youth work, have afforded spirituality greater significance in both the theory and practice of their work, dance has shown relatively little interest. The locus of what interest there has been is largely in relation to dance education and participation in dance for reasons of health and well-being. Williamson suggests that the impact of secularisation on many Western cultures has been to render 'sacred and spiritual dance a thing of the past, or indeed a thing/object belonging to the non-western' (2010: 51). That a successful contemporary, British choreographer should concern himself with the sacred and the spiritual in a direct way seems to go 'against the grain' and indeed this aspect of Khan's work has been largely overlooked. In this article I will show how Vertical Road reflects some key aspects of contemporary, progressive spirituality by embodying the multicultural experiences, values and practices of its artistic collaborators and performers.

There is no singular definition of spirituality. Indeed, many contemporary texts refer to 'spiritualities' and to the pluralized nature of 'postmodern spirituality' acknowledging the frequently individualized, personal and transmutable meanings ascribed to spirituality (Erricker and Erricker 2001; Heelas 2008). Williamson (2010) gives a concise overview of the current field. Here it is appropriate to identify some of the themes recurrent in the many definitions and variations that are in play and that relate to the examination of Vertical Road that follows later.

The term spirituality derives from the Latin spiritus, generally translated as 'breath' or 'air'. It relates to spirit as 'the animating or vital principle in man' (OED 2011) and is often expressed as a search for purpose and meaning in life. Searching and journeying are common ways of describing spiritual pursuits and aspirations. Spirituality may be said to encompass the experiences, thoughts, feelings and behaviours that arise from the search for 
what is sacred in life (Larson et al 1998). Many aspects of an individual's life may be sacred or 'sacralized' by virtue of the high value and special respect afforded them. 'Virtually anything can become sacred if people view it as such. God can be considered sacred, but so can community, finding meaning and personal relationships' (Kraus 2009 in Williamson 2010: 39). Life-itself may be sacred (Heelas 2008: 43). If, as Williamson puts it, 'in contemporary contexts the sacred floats freely, finding expression in variant secular activities' (2010: 42) then it is clear that spirituality, the search for the sacred, is not confined to religion.

Spirituality extends beyond traditional forms of religion, which are viewed by some as inherently authoritarian and exclusive (Lynch 2007: 23). Spirituality may afford an individual more freedom in terms of the practices, identities, experiences and relationships it legitimizes (Lynch 2007: 41). So, though religion gives expression to spirituality it does not have a monopoly on it. Other vehicles may allow more creative expressions of spirituality. Indeed artists may be said to practice their spirituality through their art (Heelas 2008: 43; Cobussen 2008: 42) and not least through the art of movement and dance.

Traditionally and popularly spirituality is conceived of as dealing more or less exclusively with other worldly, transcendent, immaterial phenomena and with the pursuit of perfection. Recently, however, more emphasis has been given to the grounded, embodied and essentially human nature of spiritual practices leading to 'a spirituality, which animates and activates human beings to cope with the world rather than to inwardly escape from it' (Teilhard de Chardin in Erricker and Erricker 2001: 6). Contemporary forms of spirituality, such as progressive spirituality, advocate active engagement with the environment and society whilst, at the same time, resisting the secularization brought about by, for example, technology and consumerism (Lynch 2007).

Williamson suggests that progressive spirituality provides a useful paradigm for identifying broad themes in contemporary spirituality (2010: 55) and makes a persuasive case for its relevance to current dance practice- in her case somatic movement dance education. I suggest that some of the key themes of progressive spirituality (as summarized by Lynch 2007) provide a useful framework for examining Vertical Road-an example of current theatrical dance performance. 
Lynch suggests that progressive spirituality is emerging as a spiritual ideology with identifiable values and beliefs and the potential to unite across and beyond religious traditions (2007: 20-21). In summarizing the key tenets of progressive spirituality, Lynch is at pains to point out that these are not simply abstract ideas but aspects of a lived ideology and part of spiritual and cultural practices (2007: 41). In fact he advocates that 'serious scholarship on changing patterns in religion and spirituality in the West can only really proceed on the basis of careful reading of cultural products-like books, websites, magazines' (Lynch 2007: 7-8) to which I would add-and dances.

Lynch sees the fundamental tenets of progressive spirituality as organized around common assumptions about the divine, nature, humanity and religious traditions (2007:43). He suggests that amongst religious and spiritual progressives, the divine is held to be an ineffable unity that creates and sustains an unfolding cosmos, the evolution and workings of which may be understood through scientific enquiry (Lynch 2007: 44-6). The divine, however, is not outside of this creation but within the material form and energy of the universe. Drawing ideas from quantum physics of the cosmos as an energy field, the divine is sometimes referred to as energy (Lynch 2007: 47). In this view the divine is 'that in which all things live and move and have their being' (Lynch 2007: 48) and not a separate, removed or distant entity. It follows that every living individual has the potential to experience and to know the divine through a variety of practices. The second key feature of progressive spirituality is a general concern that the natural order-those things outside of human cultural activity but influenced by it-should be respected and cared for and that humanity should recognize the responsibilities of its role within a complex ecosystem. Thirdly, progressive spirituality views humanity as an aspect of divine life. 'In contrast to religious views of the self as inherently flawed or sinful, progressive spirituality sees the self as another manifestation of the divine intelligence and energy' (Lynch 2007: 55). A spiritual journey, therefore, is not in search of something entirely outside of oneself but also for the sacred within the self and others. This view of spirituality emphasizes the underlying connectedness of humanity and values the complexities of embodied experience. Fourthly, progressive spirituality values a range of religious traditions in so far as they share its core assumptions about the divine, nature and humanity (Lynch 2007: 61). Religious diversity is welcomed and different practices and modes of expression freely 
drawn upon. So, as a common ideological framework, this makes collaboration and exchange between different cultures of religious belief and spiritual practice not only possible but also desirable. With this broad ethos of progressive spirituality in mind let me now turn to a consideration of Akram Khan's Vertical Road.

Vertical Road is a 70 minute ensemble performance with a specially commissioned score by Khan's long time collaborator, the composer Nitin Sawhney. The set, an opaque plastic backdrop stretched across the full height and width of the performance space, was designed by Jesper Kongshaug (who, with Fabiana Piccioli, also designed the lighting) and Kimie Nakano (who also designed the costumes). Ruth Little was dramaturge and Farooq Chaudhry was producer. The work was made for and with a cast of eight performers reflective of the culturally interactive nature of the company: Eulalia Ayguade Farro (Spain), Konstatina Efthymiadou (Greece) ${ }^{\mathrm{i}}$, Salah El Brogy (Egypt), Ahmed Khemis (Algeria/Tunisia), Young Jin Kim (South Korea) ${ }^{\mathrm{ii}}$, Yen-Ching Lin (Taiwan), Andrej Petrovic (Slovakia) and Paul Zivkovich (Australia). ${ }^{\text {iii }}$

These performers brought rich, embodied resources of cultural and performance capital to the devising process-a process which they describe as inclusive, improvisational and collaborative (Zivkovich in Mackrell 2010; Farro in Jennings 2010). Khan is clear that dancers bring 'their own language; their own creativity' (Khan in Jaggi 2010) to devising and performance and that, as choreographer and director, he builds 'on the dancer's experiences of life, of dance, of walking, of family, of the past, of the weather' (Khan in Ellis 2004). A key example of this is the role created in Vertical Road for and with Salah El Brogy. In 2009 Khan saw El Brogy performing in Beirut, Lebanon. ${ }^{\text {iv }}$ Khan was struck because, as he states,

The quality of his performance - even of steps that were of little interest — drew my attention. I asked him what he was thinking of onstage, and he replied that he was not thinking of anything, simply speaking to God. It was enough for me to hire him immediately. (Khan in Boccadoro 2011).

El Brogy's embodied understanding of Sufism and of Sufi dancing, folk dance and improvisation was the impetus for a powerful and distinctive performance at the core of Vertical Road. 


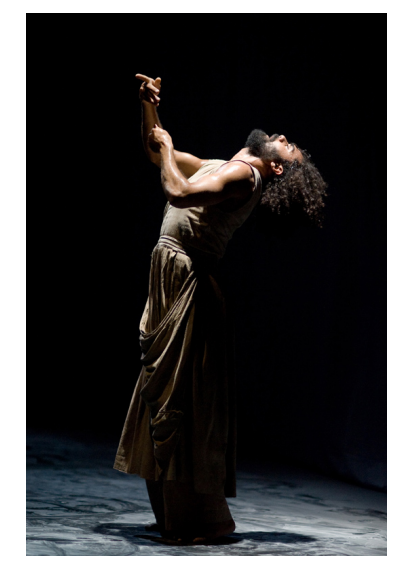

Figure 1: Salah El Brogy in Vertical Road. Photo: Laurent Ziegler.

El Brogy occupies a central role of a traveller, prophet or 'searcher for truth' (Crompton 2010). Seen by reviewers as mystical and other-worldly (Boccadoro 2011) he gives performances that are visceral, urgent and imbued with the rawness that so interests Khan (Khan in Machon 2009: 113). Fellow performer, Paul Zivkovich has said of him, 'the movement and the rhythm come from a different place for Salah, and it can be seen in the performance. His eyes close and he experiences exactly what he's in, in that moment' (in Mackrell 2010) (Figure 1). El Brogy has said that on stage it is his soul rather than his body that speaks (El Brogy 2010). El Brogy is a disciple of Sufism, that branch of Islam that emphasizes inner spirituality and unity with God. Movement and dance are significant spiritual practices in Sufism, perhaps most well known as part of the sama ceremony where dance is practiced as a turning prayer or meditation.

Khan's own dance background is in contemporary dance and in Kathak. From the age of seven Khan trained, and still continues his own daily practice, in Kathak. This classical dance form developed mostly in Northern India where it incorporated elements of both Hindu mythology and Islamic philosophy (Iyer 1997). To learn Kathak means to learn 'the philosophies and heritage of India' (Anwara Khan, Khan's mother, in Smith 2008: 81) and requires an understanding of Indian spiritual and religious ideas. Indeed for many dancers Kathak is as much a spiritual as an artistic practice (see Shah 1998). Khan describes Kathak as a 'mental, physical and spiritual approach' in which 'the physical training of the body is the final necessity' (Khan in Haroon 2010).

Khan continues to perform Kathak as a solo artist but also explores the interface between contemporary and Kathak (Norridge 2010: 416) mostly in ensemble and 
collaborative works that are generally viewed as contemporary performance and which have contributed significantly to the development of British dance (Mitra 2009: 54). Khan has said 'when I put my bells on there's a sense of spirituality, which is important to me. Classical is me in search of the spiritual, and contemporary is me searching for science, destroying and taking things apart' (Khan in Jaggi 2010). Increasingly these interests, in the spiritual and the scientific, are brought together in his contemporary work. For example, in Kaash (2002) Khan and his collaborators explored scientific ideas about the nature of the universe, including dark matter and black holes, by focusing on Shiva, the Hindu God of creation and destruction (Burt 2004a; Sanders 2004: 7). Burt argues that Kaash expressed 'superhuman divine imagery' not through traditional performative practices but in Khan's negotiation of 'Indian and Western movement ideologies' (Burt 2004b: 105). Such cross-cultural negotiation has been much discussed in relation to Khan's work especially with regard to his movement vocabulary, movement quality and aesthetics; these being 'the unintended consequence of learning two physical systems which became overwritten in his muscles' (Sanders 2008: 60). Vertical Road also demonstrates elements of the hybrid movement language that Khan has developed from the 'confusion', as he puts it (Perron 2008: 39), of contemporary and Kathak training: elements such as spins and twists, especially of the upper body; fluid use of arms and hands which spiral and carve space about the head and shoulders; complex rhythms with exact timing; sudden and statuesque stillness. I suggest, however, that more prominent in Vertical Road is a negotiation of cultural values and world views especially in relation to aspects of Eastern (Islamic) and Western (Christian) spiritual traditions. Khan has said, 'classical to me is clarity where the boundaries are clear and visible. Contemporary is chaotic' (Vasudevan 2002: 18). It is the chaos that contemporary dance affords that provides rich opportunities to explore the dichotomy and ambiguity between, for example, material and immaterial, life and death, past and present, self and others. This is what Khan seems interested to do in Vertical Road.

At the start of Vertical Road is a sort of prologue in which the figure of El Brogy is just visible behind the opaque backdrop (Figure 2). To sounds reminiscent of softly running water he strikes the backdrop as if trying to arouse the seven figures sitting crossed-legged, heads bowed to the ground, in front of the scrim. 


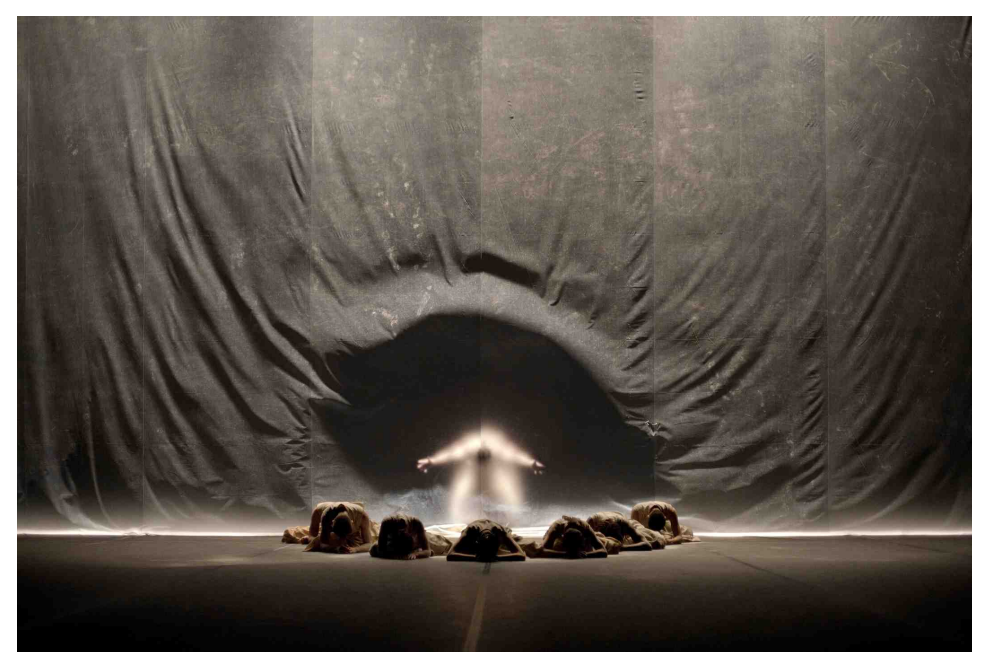

Figure 2: Vertical Road Photo: Laurent Ziegler.

El Brogy draws large, spiralling circles and writes in a cursive (perhaps Arabic) script on the scrim. As rumbling sounds build to a threatening crescendo, his attempts to communicate with those on the other side of the scrim become increasingly urgent. Perhaps in frustration at the lack of response he slams his head against the scrim and suddenly all is dark and silent. As the sound of wind whistles eerily and light returns El Brogy is seen on the stage space where the seven dancers are now standing motionless. He gently examines them and the seven stone tablets which are standing on end at the front of the stage. As he tumbles the tablets, which clatter sequentially to the ground, a metronome begins to tick and the dancers jerk violently into action, clouds of dust rising from their hair and clothes (Figure 3).

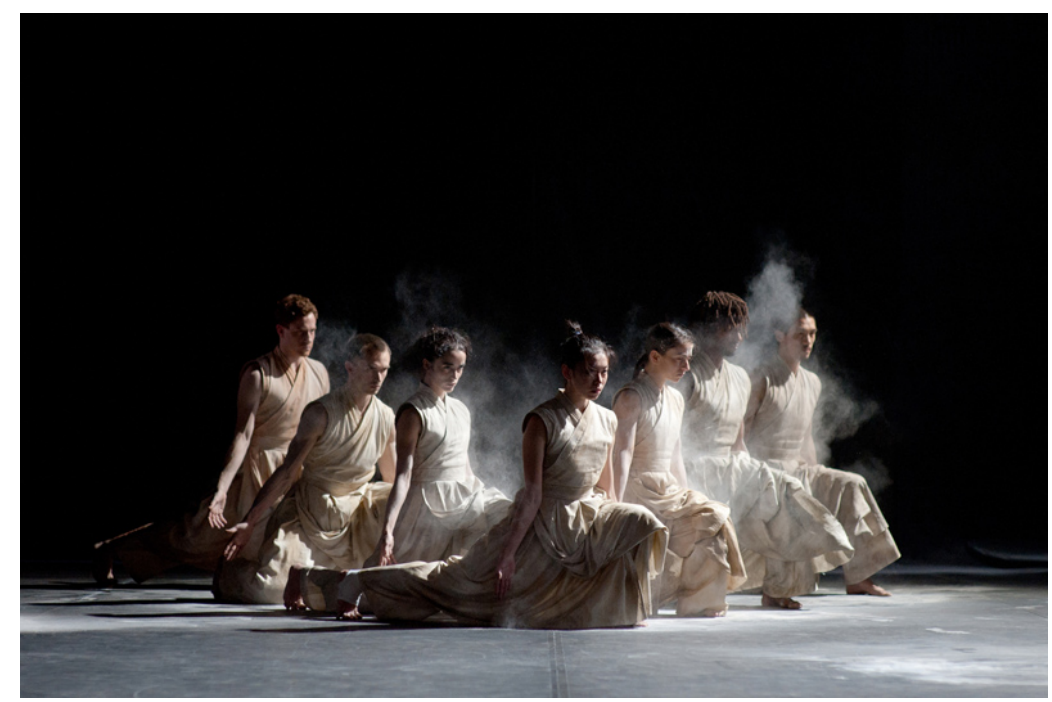

Figure 3: Vertical Road Photo: Laurent Ziegler. 
This begins a long, mostly unison, ritualistic dance to Sawhney's driven, percussive score. The seven dancers feverishly wipe away the dust clinging to their clothes and bodies, strike the ground, twist their torsos and thrust out their arms as if struggling to free themselves from unseen bonds (Figure 4).

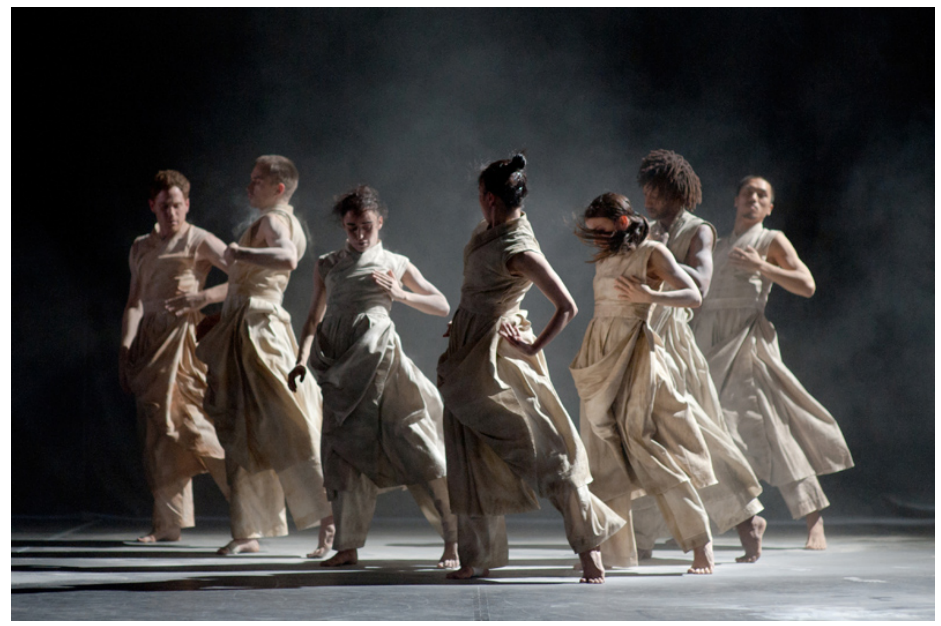

Figure 4: Vertical Road Photo: Laurent Ziegler.

El Brogy is sometimes drawn into their insistent, martial like movement seeming to absorb its dynamic into his own throbbing, percussive action. At other times he seems to pull the other dancers to him; a tall, commanding figure around which the often earth bound dancers gather (Figure 5).

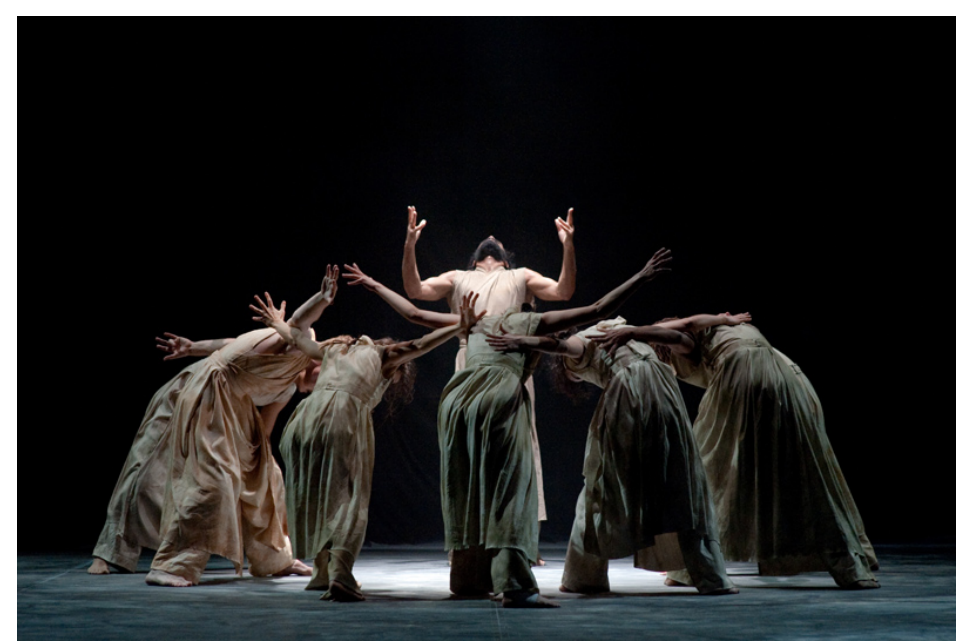

Figure 5: Vertical Road Photo: Laurent Ziegler. 
They crawl and scrabble, insect like around his feet, beating their bodies causing dust to fly. At one point, in their midst El Brogy begins to spin, one palm turned upwards whilst, with the fingers of his other hand, he beckons as if inviting an ethereal force into himself on behalf of the group. Some critics have likened this to The Rite of Spring (Newman 2010; Gray 2010) and indeed the sense of a communal and powerful ritual is overwhelming. Having risen to life from the dry, dusty earth the dancers seem to embody the notion of divinity as pure energy, coursing through individual bodies and holding them together in a vortex of movement (Figure 6).

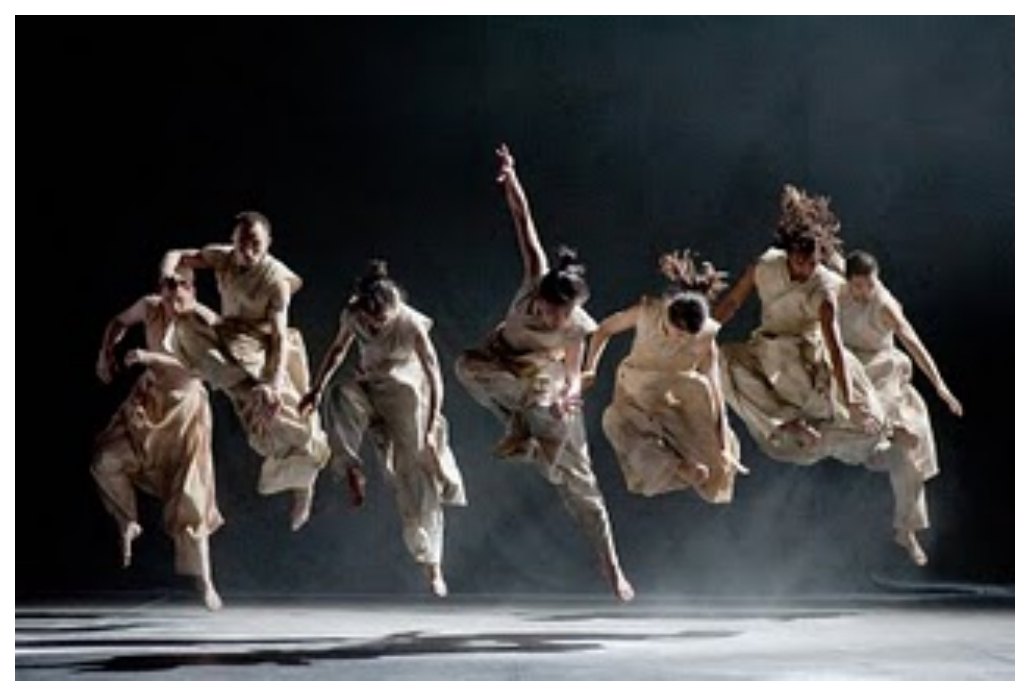

Figure 6: Vertical Road Photo: Laurent Ziegler.

This energy that both animates and connects is also apparent in the following section of Vertical Road. As the force, which seems to have driven the group gradually ebbs away, the sound of wind howling through an empty landscape returns and the dancers are left standing quietly. El Brogy makes to leave. As he does so the hem of his long gown is caught, and he is stopped, by one of the female dancers, Konstatina Efthymiadou. The vignette created brings to mind the incident related in the gospel according to Matthew of a woman who, in a crowd of people, caught hold of the hem of Jesus' cloak in order to be healed (Matthew 9:20, Revised Standard Version). In Vertical Road this action initiates a trio in which El Brogy and Efthymiadou are joined by Paul Zivkovich and explore ways in which their actions, sometimes deliberately but often unwittingly, affect one another. The outcome is at times playful and mischievous but at other times manipulative and disturbing. So, a seemingly careless wave of El Brogy's hand sends a violent shudder through Zivkovich's body even though they are some way apart from each other. Khan seems to be 
expressing the essential connectedness of humanity, a concern he has voiced in interviews about Vertical Road where he has described Vertical Road as a 'search of what it might mean to be connected' (Newman 2010). He has posed himself the question 'with the increased global communication that technology has given us, do we actually feel connected?' (Khan 2010). What connects El Brogy, Efthymiadou and Zivkovich is their awareness of and intention to animate each other. An unseen force appears to operate between them making them inescapably part of each other's world.

Khan has also said that Vertical Road is about spirituality rather than religion (Watson 2010) and nowhere is this clearer than in a section in which two duets occupy the stage at the same time and so are juxtaposed. Two male dancers, El Brogy and Ahmed Khemis, are drawn to the stone tablets which might represent religious books; repositories of spiritual authority external to and existing independently of the performers. The dancers handle them carefully and reverently. They become increasingly fascinated by and fixated with the tablets. Khemis sits crossed-legged, cradling a tablet lovingly and rocking to and fro. At the same time a male and female dancer, Andrej Petrovic and Eulalia Ayguade Farro, begin a duet, at firstly courtly but then increasingly intimate, that takes them slowly around the edge of the stage space. They appear completely engrossed with one another, rolling in intricate and gentle embraces (Figure 7).

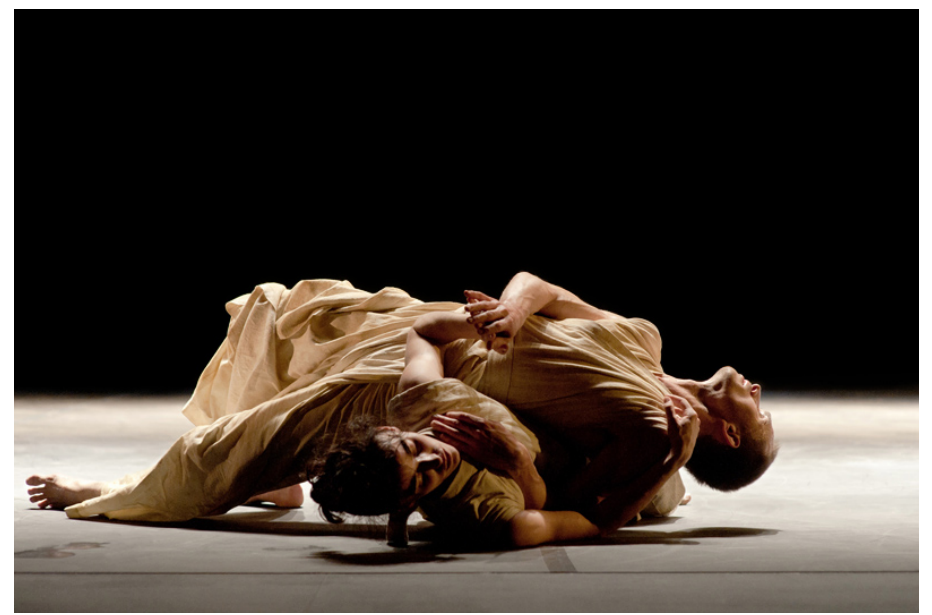

Figure 7: Andrej Petrovic and Eulalia Ayguade Farro in Vertical Road Photo: Laurent Ziegler.

Khan describes this as a love duet and specifically as ghazal (Khan 2011b). Ghazal is a poetic form now found in many languages but originating in Arabic verse. Sufi poets, including Rūmī, composed ghazals. It became a popular form in Urdu (a language of 
Northern India) and so the concept of ghazal was incorporated into Kathak. The central theme of ghazal is love. The intended recipient of love may be divine or mortal; the love expressed may be spiritual or sexual. The two are often ambiguous. For Khan the two meanings, one referring to a lover and one referring to God, were what interested him, that and 'by forming a physical, intimate relationship with another person, God existed' (Khan 2011b). As Petrovic and Farro's delicate love duet unfolds the precious tablets appear to be exerting their own force upon El Brogy and Khemis. The two men now pass the tablets between them, each contact seeming to electrify the dancers sending ripples through their bodies and throwing them into a complex series of spins and falls (Figure 8).

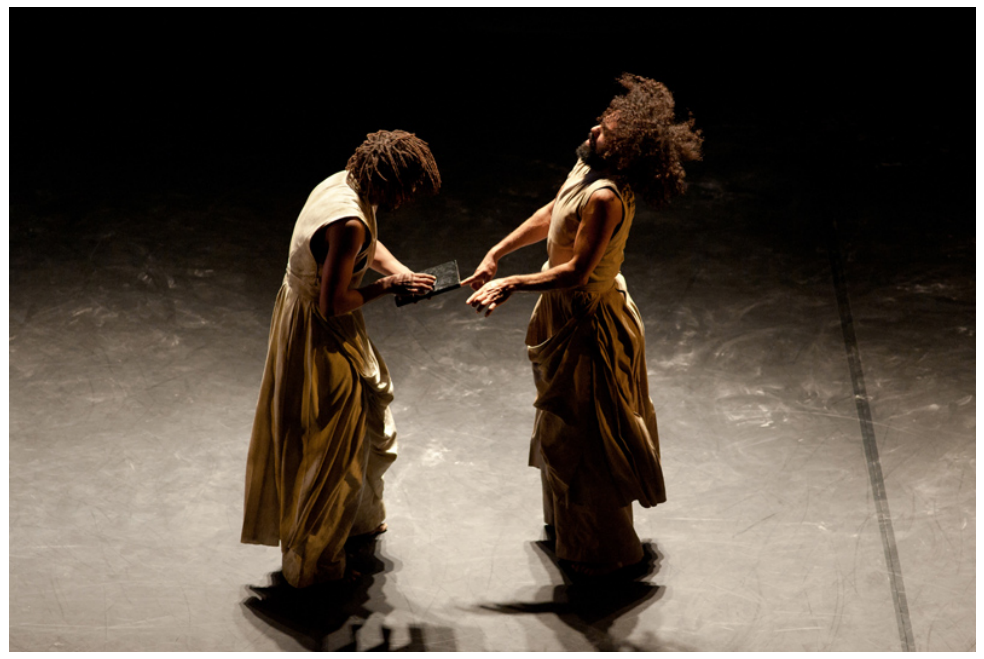

Figure 8: Ahmed Khemis and Salah El Brogy in Vertical Road Photo: Laurent Ziegler.

The men are now completely focused on the tablets, which perhaps encapsulate divine revelation, whilst Petrovic and Farro are entirely involved with each other, seeking the divine within themselves and each other. A beautiful, rhythmical melody with soaring Arabic voices envelopes both duets. Khan seems to be suggesting parallel pathways to spiritual understanding; one through embodied, sensuous experience and one through engagement with disembodied revelation.

Both duets having reached a climax, the participants experiencing revelation in their different ways, darkness falls. Sounds reminiscent of rumbling thunder and the crackling of an electric storm are heard and light flashes illuminating the motionless dancers. Gradually light floods the stage and to music that seems to emerge from sounds of gently babbling water, Yen-Ching Lin draws the dancers into a glorious section of continuous, fluid, harmonious movement. Together the dancers trace circles, spirals and waves within and 
around their bodies and through the space. They spin in ways distinctly referencing the turning meditations of Mevlevi samazens-head slightly tilted, arms out-stretched, right palm facing upwards to receive divine grace and left palm facing downwards to channel it to the earth. Their long, full skirts billow around them. The patterning of the spinning dancers is balanced and symmetrical, bringing to mind the orderly orbiting of celestial bodies. Both movement and music pulsate with the rhythmical ebb and flow of a life force in which the dancers now appear to be completely immersed. The dancers, that is apart from El Brogy. He sits downstage, outside of this life-affirming dance, quietly examining the stone tablets. One by one, whirling and twisting, the dancers leave the stage as if spun out of view by centrifugal force. El Brogy is left alone. Eventually he approaches the opaque backdrop through which the ghostly figures of the other dancers can be made out gradually fading into the distance. As El Brogy stands before the scrim water begins to drip and then to roll down it. When he reaches out to touch it the scrim falls revealing for a moment a dark void behind then leaving the stage in darkness with only the sound of gently falling water (Figure 9).

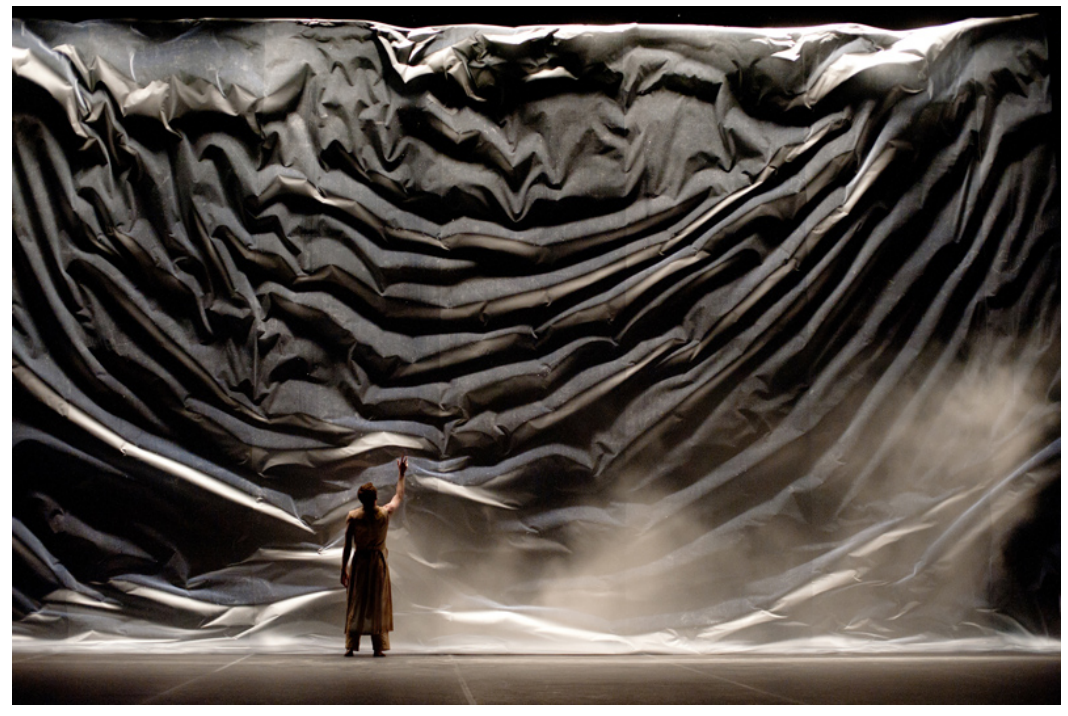

Figure 9: Vertical Road Photo: Laurent Ziegler.

The vision then of spiritual journeying that Vertical Road opens up is not the straightforward stairway to heaven that some reviewers might have us believe. Instead Vertical Road is a complex, eclectic and nuanced exploration of contemporary spirituality. There are no simple, spiritual certainties here. For example, the central character in Vertical Road, as portrayed by Salah El Brogy, is on a journey but a journey that is not 
without its complications and interruptions. For much of the piece his attention is wrested back and forth between his fellow dancers, the inanimate stone tablets and his own self absorbed, idiosyncratic movement. He seems uncertain as to where salvation lies-in relationships with others, in intellectual study, deep within himself or beyond all of these. Even the start and end points of his journey are ambiguous. He seems to be the catalyst that pulls the other dancers from their dry, dusty resting place and propels them into action. Eventually, he is abandoned as these companions pass behind the plastic scrim and fade from sight. His final gesture seems to bring the world crashing down whilst at the same time releasing a downpour of water, symbolic of bringing new life to what was once parched earth.

At play in Vertical Road are some of the ideas characteristic of progressive spirituality that were identified earlier. A particular idea is the manifestation of the divine as energy that vitalises the universe and all life within it and, as a consequence, the search for divinity in the complexities of embodied-social and sensual-experience. The Rūmì poem, which forms the programme note for Vertical Road, speaks not only of transcendence and transformation but also of a cycle of earthy, material existence. Lynch puts it particularly well when he writes that progressive spirituality is 'not so much a striving towards a state as yet unachieved, as it is a process of learning to recognize the true spiritual condition in which we are already living' (2007: 59). This seems to me to epitomize Vertical Road.

The spiritual condition that Vertical Road seeks to understand is born of an increasingly interconnected world-a world that the Akram Khan Company as a transnational organization exemplifies. Thus the creative team responsible for Vertical Road came from Europe, Asia and the Middle East. The production was sponsored by Colas, an international construction company based in France, and co-produced by cultural organisations in Abu Dhabi, Europe and Canada. In Vertical Road Khan and his collaborators drew on practices and iconography from Islamic, Christian and secular worlds to explore the nature of spiritual aspiration in a globalised, technology enhanced world. In tracing the origins of Vertical Road Khan relates an incident in Sydney, Australia when he was elbowed aside in a queue for taxis. He explains, 
I got into another taxi and felt like hearing my father's voice so I telephoned him, something I never do on tour although we're close. As I hung up after a casual chat, in Bengali, the language we use at home, the taxi stopped and the driver asked, astonishingly in Bengali, whether my father was from Algichar, a small village in Bangladesh. Only 200 people in the world could know that and 195 of them live there, the other four being my parents, my sister and me, leaving the only one other person - a taxi driver at midnight on the other side of the world. (Khan in Boccadoro 2011).

The incident led Khan to reflect on whether this unlikely reunion was mere chance or an intervention by 'taxi-snatchers who were really angels in disguise' (Khan in Boccadoro 2011). It exemplifies Khan's concern with what inspires people to connect with each other. This concern is apparent throughout Vertical Road and it is fundamental to Khan's artistic endeavour and his practice. It underpins the creative collaborations that Khan acknowledges as integral to his journey as an artist (Khan 2011a). Speaking of collaboration in relation to his work generally and Vertical Road in particular, Khan describes a turning point in the process of making work when,

There is just 'us', or 'we' left behind, a collection of artists, of different disciplines, different languages, different cultures, different education, but we are all in the same room, in silence, and all our passionate gestures and fierce negotiations, have come to a standstill, and with it, a sense that we all want a single 'truth', that this journey together has to end up giving birth to our creation ... that somehow, we as individuals, are like small jigsaw pieces, but together, we form a single, but powerful and larger fuller picture. (Khan 2011a).

This eloquent description of the reality of a collective, artistic enterprise could equally be an iteration of the spiritual condition identified by contemporary spiritual progressives. It acknowledges the struggle involved in finding meaning but also celebrates the possibility of doing so through mutual identity based on shared concerns, responsibilities and aspirations.

Like the Rūmī verse that contributed to its inspiration, Vertical Road is a poetic and at times mystical reflection on our spiritual condition. Through a symbolic journey pursued in dance it reveals the spirituality of seeking that questions current attitudes to self, others and the divine.

\section{REFERENCES}


Boccadoro, P. (2011), 'Akram Khan. The making of Vertical Road'. Culturekiosque, 6 April. http://www.culturehiosque.com/dance. Accessed 16 August 2011.

Burt, R. (2004a), 'Contemporary dance and the performance of multicultural identities'. http://www.akramkhancompany.net/html/akram_essay.php?id=15. Accessed 2 November 2011.

Burt, R. (2004b), 'Kaash: dance, sculpture and the visual', Visual Culture in Britain, 5 (2), pp. 93-108.

Cobussen, M. (2008), Thresholds: rethinking spirituality through music, Aldershot: Ashgate Publishing.

Crompton, S. (2010), 'Vertical Road'. The Telegraph, 7 October.

http://www.telegraph.co.uk/culture/culturecritics/sarahcrompton. Accessed 8 October 2010.

El Brogy, S. (2010), International Dance Festival Birmingham Interview, http://www.youtube.com/watch?v=Db3EAJqcKGc. Accessed 25 October 2011.

Ellis, S. (2004), 'Dance was about breaking all the rules that were set in my body', The Guardian, 22 April.

http://www.guardian.co.uk/culture/2004/apr/22/samanthaellis.guesteditors/print. Accessed 24 October 2011.

Erricker, C. and Erricker, J. (eds.) (2001), Contemporary spiritualities: social and religious contexts, London: Continuum.

Gray, J. (2010), 'Dance scene: United Kingdom: Vertical Road', The Dancing Times, 101(1203), p. 52.

Haroon, L. (2010), 'Rhythm of heritage', Gulf News, 19 February. http://gulfnews.com/artsentertainment. Accessed 2 November 2011.

Heelas, P. (2008), Spiritualities of life. New Age romanticism and consumptive capitalism, Oxford: Blackwell Publishing.

Iyer, A. (1997), 'South Asian dance: the traditional/classical idioms'. Choreography and Dance, (4), pp. 5-17.

Jaggi, M. (2010), 'A life in dance: Akram Khan', The Guardian, 25 September. http://www.guardian.co.uk/culture/2010/sep/27/akram-khan-dance-life/print. Accessed 24 October 2011.

Jennings, L. (2010), 'Akram Khan: 'Despite the chaos, we're all connected'. The Guardian, 12 September. http://www.guardian.co.uk/stage/2010/sep/12/akram-khan-vertical-roadjennings. Accessed 14 September 2010.

Khan, A. (2010), Interview with Jayne Stevens, 15 September. Curve Theatre, Leicester.

Khan, A. (2011a), ' Keynote address: the art of collaboration', Congress of The International Society for the Performing Arts, Times Center, New York, 11 January. http://www.akramkhancompany.net/html/akram_essay.php?id=14. Accessed 2 November 2011.

Khan, A. (2011b), Interview with Jayne Stevens, 1 November. Sadlers Wells Theatre, London. 
Larson, D., Swyers J.P., McCullough M E. (eds.) (1998), Scientific research on spirituality and health: a consensus report. National Institute for Healthcare Research, Rockville.

Lynch, G. (2007), The new spirituality: an introduction to progressive belief in the twentyfirst century, London: Tauris.

Machon, J. (2009), 'Akram Khan: the mathematics of sensation: the body as site/sight/cite and source'. In J. Machon, ed. (Syn)aesthetics: redefining visceral performance. Basingstoke: Palgrave Macmillan.

Mackrell, F. (2010), 'Akram Khan's Vertical Road'. ArtsHub, 29 September. http://www.artshub.com.au/au/newsPrint.asp?sId=182476. Accessed 1 October 2010.

Mitra, R. (2009), 'Dancing embodiment, theorising space: exploring the 'third space' in Akram Khan's Zero Degrees'. In A. Lepecki and J. Joy, eds., Planes of composition: dance, theory and the global, London: Seagull Books, pp. 40-63.

Newman, B. (2010), ‘Reviews: Akram Khan Company’ Dance Magazine 84 (12), pp. 8687.

Norridge, Z. (2010)' 'Dancing the multicultural conversation? Critical responses to Akram Khan's work in the context of pluralist poetics', Forum for Modern Language Studies, 46 (4), pp. 415-430.

OED (2011) Oxford English Dictionary $3^{\text {rd }}$ on-line ed. http://www.oed.com. Accessed 30 November 2011.

Perron, W. (2008), 'Global dance: east and west meet in the body of Akram Khan', Dance Magazine, 82 (11), pp. 38-40.

Sanders, L. (2004), Akram Khan's Rush: creative insights, Alton: Dance Books.

Sanders, L. (2008), 'Akram Khan's $m a$ (2004): an essay in hybridisation and productive ambiguity'. In J. Lansdale, ed. Decentring dancing texts. The challenge of interpreting dances. Basingstoke: Palgrave Macmillan.

Shah, P. (1998), 'Transcending gender in the performance of Kathak', Dance Research Journal, 30 (2), pp.2-17.

Smith, L. (2008), 'In-between spaces': an investigation into the embodiment of culture in contemporary dance', Research in Dance Education, 9 (1), pp.79-96.

Vasudevan, P. (2002), 'Clarity within chaos', Dance Theatre Journal, 18 (1), pp. 16-19.

Watson, K. (2010), 'Akram Khan: quest for a way to connect'. Metro, 13 September 2010. http://www.metro.co.uk/lifestyle/840797-akram-khan-quest-for-a-way-to-connect. Accessed 15 September 2010.

Williamson, A. (2010), 'Reflections and theoretical approaches to the study of spiritualities within the field of somatic movement dance education'. Journal of Dance and Somatic Practices. 2 (1), pp.35-61.

Acknowledgement: I am indebted to Akram Khan and members of the Akram Khan Company for the generous way in which they allowed me to interview them and observe 
rehearsals and for providing recordings of Vertical Road. I am grateful to Laurent Ziegler for permission to include photographs of Vertical Road.

How to cite this article: Stevens, J. (2012) "What you cannot imagine': spirituality in Akram Khan's Vertical Road', Journal of Dance \& Somatic Practices 4: 1, pp. 43-57, doi: 10.1386/jdsp.4.1.43_1

(C) Jayne Stevens, 2012

i Konstandina Efthymiadou was later replaced by Sade Alleyne (from the UK)

ii Young Jin Kim was later replaced by Sung Hoon Kim (from South Korea)

iii Paul Zivkovich was later replaced by Elias Lazaridis (from Greece)

iv Salah El Brogy and Ahmed Khemis both performed solos in the Arab Dance Platform as part of Beirut International Platform of Dance 23 - 26 April 2009. 